Disclosure of Interest: $H$. Choi Grant/research support from: AstraZeneca, Consultant for: Horizon Pharma, Selecta, R. Johnson: None declared, A. Yeo Consultant for: Horizon Pharma, P. Lipsky Consultant for: Horizon Pharma DOI: 10.1136/annrheumdis-2018-eular.5616

\section{FRI0238 THE LEVEL OF LEPTIN IN PATIENTS WITH GOUT AND ITS ASSOCIATION WITH THE GOUT ACTIVITY SCORE}

I. Orlova, M. Stanislavchuk. Department of Internal Medicine \#1, National Pirogov Memorial Medical University, Vinnytsya, Ukraine

Background: Leptin is a cytokine-like hormone mainly produced by adipose tissue. Its role in inflammation, obesity, diabetes mellitus, and cardiovascular pathology is well known. ${ }^{2}$ Most of these pathological conditions usually acompany gout but role of leptin in gout remains on the discussion.

Objectives: To determine the level of leptin in patients with gout and evaluate its association with the disease activity.

Methods: Study involved 151 patients with gout ( $100 \%$ men), aged (mean \pm SD) $52.4 \pm 9.2$ years, with a disease duration $8.9 \pm 6.6$ years. In 51 (33.7\%) was diagnosed tophaceous gout. Contol group was represented by 31 healthy subjects. Diagnosis of gout was based on the ACR/EULAR 2015 criteria. The disease activity was determined by the Gout Activity Score (GAS), ${ }^{2}$ the intensity of the pain - by the visual analogue scale $\left(V_{\text {AS }}\right.$ pain $)$. Leptin in serum was determined by ELISA. Results: The level of leptin in patients with gout was 2 times higher compare to those in the control group $(6.6 \pm 4.3 \mathrm{vs} 3.0 \pm 1.4 \mathrm{ng} / \mathrm{ml})$. The number of attacks in the last year was $3.9 \pm 2.7$, number of affected joints was $8,1 \pm 5,4$, and uric acid in serum (sUA) was $8.1 \pm 2.0 \mathrm{mg} / \mathrm{dl}$. Mean value of $\mathrm{VAS}_{\text {pain }}$ in gout patients was 5.4 $\pm 2.4 \mathrm{~cm}$, and disease activity by GAS $-5.9 \pm 2.1$. Regarding GAS we divided our patients in three groups: low activity (GAS $<25$ th percentile), moderate activity (between 25th and 75th percentile) and high activity ( $>75$ th percentile). In 36 patients with high disease activity (GAS $>7.4$ ) the level of leptin was the highest $(11.7 \pm 4.7 \mathrm{ng} / \mathrm{ml})$, whereas in patients with moderate activity (GAS 4.5-7.4; $\mathrm{n}=77$ ) and in patients with low disease activity (GAS <4.5; $\mathrm{n}=38$ ) it was $5.3 \pm 2.6 \mathrm{ng} / \mathrm{ml}$ and $3.9 \pm 1.4 \mathrm{ng} / \mathrm{ml}$, respectively. The difference in leptin levels between all groups was significant $(p<0.01)$. The level of leptin correlated with the number of gout attacks $(r=0.41)$, number of affected joints $(r=0.55)$, sUA $(r=0.39)$, VAS pain $(\mathrm{r}=0.35)$, and $\mathrm{GAS}(\mathrm{r}=0.69)$.

Conclusions: Association of increased leptin level with high gout activity may indicate possible pathogenic role of leptin in gout. GAS is reliable and sensitive clinical tool for determining disease activity in patients with gout.

\section{REFERENCES:}

[1] Jung UJ, Choi MS. Obesity and its metabolic complications: the role of adipokines and the relationship between obesity, inflammation, insulin resistance, dyslipidemia and nonalcoholic fatty liver disease. International journal of molecular sciences 2014;15(4):6184-6223.

[2] Scirè CA, Carrara G, Viroli C, Cimmino MA, Taylor WJ, Manara M, Matucci-Cerinic M. Development and first validation of a disease activity score for gout. Arthritis care \& research 2016;68(10):1530-1537.

Disclosure of Interest: None declared

DOI: 10.1136/annrheumdis-2018-eular.4528

\section{FRI0239 ABSOLUTE NUMBERS OF PERIPHERAL TH17 AND TH2 CELLS INCREASED IN PATIENTS WITH GOUT}

J. Yuan ${ }^{1}$, L. Zhao ${ }^{2}$, J. Luo ${ }^{2}$, C. Gao ${ }^{3}$, X. Li ${ }^{2}$, H. Gao ${ }^{2}$, L. Shang ${ }^{1}$, Q. Li ${ }^{1}$. ${ }^{1}$ The second hospital of Shanxi Medical University, Taiyuan, China; ${ }^{2}$ Department of Rheumatology, The second hospital of Shanxi Medical University, Taiyuan, China; ${ }^{3}$ Department of Pathology, Brigham and Women's Hospital, Harvard Medical School, Boston, USA

Background: Gout is generally considered as an acute or chronic inflammatory disease of the joints due to deposition of crystals of monosodium urate (MSU). However, crystals of MSU do not always elicit inflammation in joints, suggesting that the immunological basis is required for the development of gouty arthritis. Although T helper 17 (Th17) and regulatory T cell subsets in CD4 $+\mathrm{T}$ cells have been reported to play a key role in autoimmune diseases, their status in peripheral blood of gout patients are rare studied.

Objectives: Our present study is to explore whether the absolute numbers of peripheral CD4 +T subsets, especially Th17 cells and CD4 +CD25+FOXP3T regulatory (Treg) cells, is abnormal in gout.
Methods: A total of 72 patients with gout ( 70 male/2 female) and 41 age-sexualmatched controls were recruited from the Second Hospital of Shanxi Medical University (from March 1 st in 2016 to July 30th in 2017). Of these, 72 patients were categorised as acute gout who had redness, swelling, warmth and pain at the same time (Group1; $\mathrm{n=18}$ ) or as acute gout without redness and warmth (Group2 $\mathrm{n}=52$ ). All patients fulfilled 2015 Gout classification criteria developed by the American College of Rheumatology (ACR) and the European League Agains Rheumatism (EULAR). Patients with a history of other autoimmune diseases, nephropathy, cancer, infectious processes, or hematopathy were excluded. The detail medical histories were collected, comprehensive laboratory examinations were performed, and then the differences between the patients and controls were investigated. The concentrations of CD4 +T cell subsets (the absolute numbers of Th1, Th2, Th17 and Treg cells) in peripheral blood were measured by flow cytometry combined with internal standard beads and then the ratios of Th1/Th2 and Th17/Treg were calculated.

Results: The duration of their disease was $46.73 \pm 54.92$ (Group1), or 61.54 \pm 70.51 (Group2) months. The white blood cells (WBCs) and neutrophils in gout blood were significantly higher than those in controls $(P<0.01)$ and ESR in Group1 was obviously increased $(p=0.033)$. Levels of Total T lymphocyte counts (CD3 +CD19-), Total B lymphocyte counts (CD3-CD19+) and Helper T cells (CD3 $+\mathrm{CD} 4+$ ) were increased in Group2 (all $p<0.05$ ). Nevertheless, there was no differ ence between Group1and healthy controls. The absolute number of peripheral Th2 in gout (both Group1 and Group2) was higher than that in healthy controls $(p=0.001)$. Most importantly, the absolute number of peripheral Th17 cells was significantly increased in gout patients in Group2 $(p=0.006)$ while, in Group1, the absolute number of Treg cells decreased despite no statistical significance $(P>0.05)$.

Abstract FRI0239 - Table 1. Lymphocyte subsets of Gout Patients \& Normal Persons

\begin{tabular}{|c|c|c|c|c|c|}
\hline & Groupl 1 & Group2 2 & Normal & $\mathbf{F}$ & P.values \\
\hline $\mathrm{N}$ & 18 & 52 & 41 & & \\
\hline Toeal T cells,CD3+CD19- (oell/pL) & $1475.50(1234.50)$ & $1538.43(894.50)$ & $1360.59(488.84)^{6}$ & 4.954 & 0.084 \\
\hline Total B cells,CD3-CD19+ $(\boldsymbol{\alpha e l l} / \mathrm{hL})$ & $200.51(195.92)^{*}$ & $300.50(224.27)$ & $191.04(103.48)^{\circ}$ & 13.610 & 0.001 \\
\hline Th cells, $\mathrm{CD}_{3}+\mathrm{CD} 4+\quad$ (cell/ $/ \mathrm{LL}$ ) & $783.34(527.75)$ & $866.50(520.75)$ & $625.84(187.63)$ & 13.134 & 0.001 \\
\hline Ts cells, CD\&+T (eell/pL $)$ & $608.00(472.25)$ & $600.83(336.00)$ & $536.13(320.43)$ & 1.220 & 0.543 \\
\hline $\mathrm{Th} / \mathrm{Ts}, \mathrm{CD} 3+\mathrm{CD} 4+\mathrm{CD} 8+\mathrm{T}$ & $1.15(0.31)$ & $1.50(0.91)$ & $1.11(0.63)^{e}$ & 11.625 & 0.003 \\
\hline 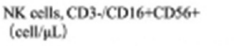 & $278.00(208.75)$ & $311.70(187.58)$ & $340.59(280.05)$ & 2.780 & 0.249 \\
\hline 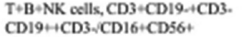 & $2148.00(1501.23)$ & $2253.00(1006.00)$ & $1918.47(739.65)^{6}$ & 6.093 & 0.048 \\
\hline
\end{tabular}

(1) were

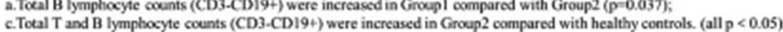

Abstract FRI0239 - Table 2. CD4+ T cell subsets of Gout Patients \& Normal Persons

\begin{tabular}{|c|c|c|c|c|c|}
\hline & Groupl & Group2 & Normal & $\mathbf{F}$ & P.values \\
\hline $\mathrm{N}$ & 18 & 52 & 41 & & \\
\hline Thl cells,IFN-y (oel1/pLL) & $63.24(126.68)$ & $115.03(183.53)$ & $125.72(98.01)$ & 1.610 & 0.447 \\
\hline Th2 cells,ll-4 (oell//LL) & $12.92(16.62)$ & $11.38(11.16)^{6}$ & $7,44(5.88)^{6}$ & 12.379 & 0.002 \\
\hline Th17 cells, $1 \mathrm{~L}-17 \quad$ (cell/ $/ \mathrm{L})$ & $6.79(12.77)$ & $11.07(9.37)$ & $7.48(5.87)^{t}$ & 7.131 & 0.028 \\
\hline Treg cells, $\mathrm{CD} 4+\mathrm{CD}_{2} \mathrm{~S}+\mathrm{FoxP}_{3}+($ cell/ $/ \mathrm{LL})$ & $23.62(28.06)$ & $30.25(20.53)$ & $30.22(16.72)$ & 2.032 & 0.362 \\
\hline $\mathrm{Th} 1 / \mathrm{Th} 2, \mathrm{IFN}-\boldsymbol{p} \mathrm{IL}-4$ & $7.14(7.66)$ & $8.95(14.49)^{6}$ & $16.17(20.13)^{c}$ & 16.288 & 0.000 \\
\hline Th17/Treg, IL-17/CD25+FoxP, & $0.29(0.83)$ & $0.40(0.43)$ & $0.24(0.20)^{6}$ & 6.986 & 0.030 \\
\hline
\end{tabular}

Conclusions: The increase of peripheral Th2 and Th17 cells led to an imbalance of CD4 +T cell subsets may correlate with gouty inflammation in an undefined way. The elevation of Th2 and Th17 cells may serve as important reference indices for gout attack and a target of gout treatment. Moreover, Th17 may contribute to the persistence of the disease.

\section{REFERENCE:}

[1] Zhou Z, Li X, Li H, Guo M, Liu S, Li C. Genetic Analysis of IL-17 Gene Polymorphisms in Gout in a Male Chinese Han Population. PLoS One [Internet] 2016;11(2):e0148082.

Disclosure of Interest: None declared DOI: 10.1136/annrheumdis-2018-eular.2248 